\title{
Integrated Proteomic and Metabolomic Profiling of Phytophthora cinnamomi Attack on Sweet Chestnut (Castanea sativa) Reveals Distinct Molecular Reprogramming Proximal to the Infection Site and Away from It
}

\author{
Iñigo Saiz-Fernández ${ }^{1}{ }^{(\mathbb{D}}$, Ivan Milenković ${ }^{2,3}$, Miroslav Berka ${ }^{1}$, Martin Černý ${ }^{1}{ }^{(}$, \\ Michal Tomšovský ${ }^{2}$ (D) Břetislav Brzobohatý ${ }^{1}$ and Pavel Kerchev ${ }^{1, *}$ \\ 1 Phytophthora Research Centre, Department of Molecular Biology and Radiobiology, Faculty of AgriSciences, \\ Mendel University in Brno, Zemědělská 3, 61300 Brno, Czech Republic; saizfern@mendelu.cz (I.S.-F.); \\ miroslavberka94@gmail.com (M.B.); martincerny83@gmail.com (M.Č.); brzoboha@ibp.cz (B.B.) \\ 2 Phytophthora Research Centre, Department of Forest Protection and Wildlife Management, Faculty of \\ Forestry and Wood Technology, Mendel University in Brno, Zemědělská 3, 61300 Brno, Czech Republic; \\ ivan.milenkovic@mendelu.cz or ivan.milenkovic@sfb.bg.ac.rs (I.M.); michal.tomsovsky@mendelu.cz (M.T.) \\ 3 Forest Protection, Department of Forestry, Faculty of Forestry, University of Belgrade, Kneza Višeslava 1, \\ 11030 Belgrade, Serbia \\ * Correspondence: pavel.kerchev@mendelu.cz
}

Received: 9 October 2020; Accepted: 10 November 2020; Published: 12 November 2020

\begin{abstract}
Phytophthora cinnamomi is one of the most invasive tree pathogens that devastates wild and cultivated forests. Due to its wide host range, knowledge of the infection process at the molecular level is lacking for most of its tree hosts. To expand the repertoire of studied Phytophthora-woody plant interactions and identify molecular mechanisms that can facilitate discovery of novel ways to control its spread and damaging effects, we focused on the interaction between P. cinnamomi and sweet chestnut (Castanea sativa), an economically important tree for the wood processing industry. By using a combination of proteomics, metabolomics, and targeted hormonal analysis, we mapped the effects of P. cinnamomi attack on stem tissues immediately bordering the infection site and away from it. P. cinnamomi led to a massive reprogramming of the chestnut proteome and accumulation of the stress-related hormones salicylic acid (SA) and jasmonic acid (JA), indicating that stem inoculation can be used as an easily accessible model system to identify novel molecular players in P. cinnamomi pathogenicity.
\end{abstract}

Keywords: sweet chestnut; Phytophthora cinnamomi; proteomics; metabolomics

\section{Introduction}

Sweet chestnut (Castanea sativa Mill.) is one of the most ecologically and economically important tree species from the Fagaceae family that is autochthonous in Southern Europe and in Asia Minor. It is widely grown in planted and coppice forests for the wood processing industry, for ecological protection purposes, as amenity and ornamental tree, and for nut production [1-3]. Sweet chestnut is endangered by two major disease threats, chestnut blight and ink disease. Ink disease is caused by the pathogens from the Phytophthora genus that are fungi-like organisms within the SAR supergroup, inflicting significant economic and ecological losses in chestnut forests [4]. Two Phytophthora species are known as the main causes of ink disease on sweet chestnut, namely P. cinnamomi Rands and P. $\times$ cambivora (Petri) Buisman [5]. Both P. cinnamomi and P. ×cambivora are cosmopolites and polyphagous pathogens 
that attack numerous woody plants and other host species, causing significant losses worldwide [5-8]. P. cinnamomi, in particular, represents one of the most aggressive and notorious plant pathogens, which has been responsible for numerous devastating epidemics $[5,7,9]$. P. cinnamomi has been mainly associated with ink disease in Western Europe, while P. Xcambivora is the main cause of ink disease in Central and South-eastern Europe $[5,10]$. However, P. cinnamomi has also been found infecting sweet chestnut in Greece [2], suggesting that its spread may have been vastly underestimated, and that it is most likely already co-occurring together with $P$. $\times$ cambivora and slowly spreading to the other chestnut stands in Europe. Although low temperatures are a limiting factor for P. cinnamomi spreading into European forests [5], recent findings in alpine environments and its ability to sporulate at low temperatures in vitro [11] suggests that colder areas of Central and Northern Europe may be at serious risk of infection. This is of particular importance in the light of evident climate changes and projected future spread of P. cinnamomi [7].

Infection of chestnut trees with P. cinnamomi predominantly occurs through the roots, leading to root deterioration. P. cinnamomi is a hemibiotrophic oomycete which upon colonization establishes a biotrophic interaction with its host. During the biotrophic phase, the pathogen develops haustoria that facilitate reabsorption of nutrients from the host and delivery of effector proteins and small molecules that manipulate host defense [12]. Once the hyphae have spread throughout the endodermis and vascular tissue, necrotrophy can be observed $[13,14]$. Infected trees display various disease symptoms like leaf atrophy, chlorosis, wilting, flag-like appearance of wilted leaves, and tree dieback $[5,10]$. From the infected roots, the pathogen usually spreads to the collar, bark, and cambial tissues of the stems, resulting in flame-shaped bleeding cankers and lesions $[5,10]$. Despite being mainly a root pathogen, under certain conditions P. cinnamomi can also infect trunks directly via lenticels, adventitious roots, or wounds [15]. Stem inoculation has been successfully employed to determine the proteomic, metabolomic, and transcriptomic alterations caused by Phytophthora attack on several tree species [16-18]. Infection rates tend to be highest in spring when maximal cambial activity coincides with the peak in pathogen's sporulation [19]. Infected bark cells display altered shapes and plugged plasmodesmata [20]. The infection process is accompanied with callose, starch, and crystal deposition, and the establishment of a new periderm that limits secondary infection [15]. The newly formed periderm often provides only temporary protection which, once breached, allows invasion of phloem and xylem tissues. Once the xylem has been invaded, the plant faces the possibility of xylem disfunction, resulting in hydraulic failure and sudden tree death [15]. Interestingly, leaf photosynthetic rates tend to start decreasing prior to xylem failure. This decrease has been suggested to be a consequence of phloem tissue destruction (girdling), which impairs plant carbon allocation and causes starch to accumulate in the leaves, ultimately leading to photoinhibition [21].

Plants employ a diverse array of constitutive and inducible defense mechanisms that are being deployed during pathogen attack. Physical and chemical barriers, such as waxy layers and antimicrobial compounds, are often the first line of defense against invading pathogens [22]. Upon recognition of pathogen-associated molecular patterns (PAMPs), plants mount PAMP-triggered immunity (PTI). PTI is accompanied by the generation of reactive oxygen species (ROS), activation of protein kinase cascades, reinforcement of physical barriers, and production of numerous defense-related molecules [23]. Plant pathogens employ secreted effector proteins that interfere with plant defense mechanisms and facilitate infection [24]. Detection of pathogen effectors by the products of disease-resistant $R$ genes activates effector-triggered immunity (ETI). Pathogen effectors can be delivered to the apoplast (e.g., cell wall degrading enzymes and elicitins) or cytosol where they target various intracellular processes [25]. Cytosolic uptake is a key part of the infection process and many oomycete effector proteins possess N-terminal RxLR or LxLFLAK motifs that facilitate their uptake [23]. Additionally, plant proteins involved in exocytotic vesicle trafficking, such as v-SNARE or the VAMP72 family proteins, are found in the pathogenic membrane formation interfaces and contribute to plant defense by delivering anti-microbial proteins [26,27]. Plant membrane trafficking can be at the same time targeted by Phytophthora effectors in order to enhance their virulence [28-30]. Plant hormonal signaling pathways 
are commonly targeted by Phytophthora effector proteins due to their crucial roles in plant defense [15]. Moreover, filamentous plant pathogens can synthesize phytohormones and their derivatives that can manipulate and hijack the hormonal homeostasis of their plant hosts [31].

Here, we explored the molecular mechanisms associated with P. cinnamomi attack on chestnut. Stem infection was used as an easily accessible model system to probe the proteomic and metabolic response to P. cinnamomi. Our analysis revealed a significant molecular impact along the infected stem and indicated proteomic and metabolic alterations in the leaves of infected saplings. Taken together, the reported results point towards mobilization of SA and JA signaling pathways, which likely reflects the hemibiotrophic lifestyle of $P$. cinnamomi.

\section{Results}

\subsection{Stem Inoculation as a Model System to Study Phytophthora cinnamomi Infection on Chestnut}

To sidestep the limitations associated with inoculation and sampling of infected root tissues and explore alternative experimental model systems to study the interaction between P. cinnamomi and chestnut, we inoculated stems of two-year-old sweet chestnut saplings with P. cinnamomi (Figure 1A). Seven days after inoculation, the tissue proximal to the inoculation site displayed necrotic lesions, indicating active P. cinnamomi colonization. The presence of the pathogen in the living stem bordering the necrotic tissue was confirmed by extracting proteins and querying the measured peptide spectra against the $P$. cinnamomi proteome. Fourteen proteins unique for $P$. cinnamomi, such as transcriptional regulator NmrA, HIT family protein, putative secretory protein of the CAP family, and carbohydrate-active enzymes (CAZymes) were identified (Figure 1B). The rest of the identified protein families (291) originated from evolutionarily conserved sequences shared between P. cinnamomi and chestnut. No unique P. cinnamomi proteins were found in stem sections upstream of the inoculation site and in the leaves of infected plants. Taken together, the development of necrotic lesions upon P. cinnamomi inoculation and the presence of P. cinnamomi proteins in the immediate vicinity of the infection site but not away from it indicated active colonization and supported the use of chestnut stem inoculation as a viable model system to study P. cinnamomi-chestnut interaction at the molecular level.

A

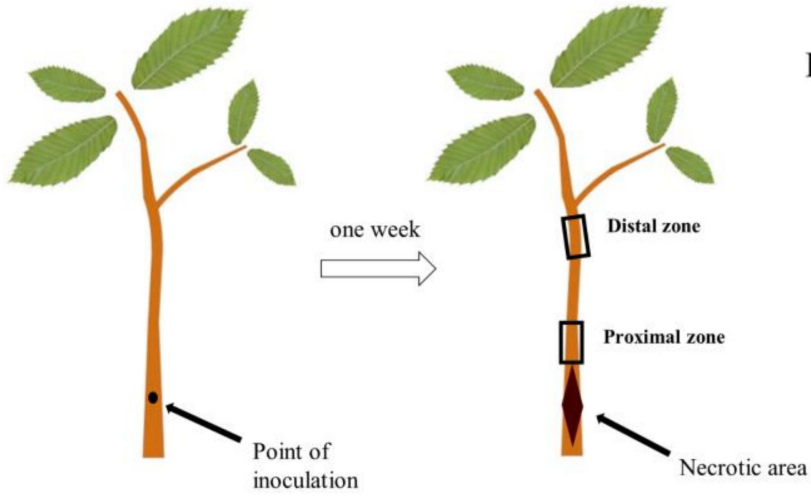

B

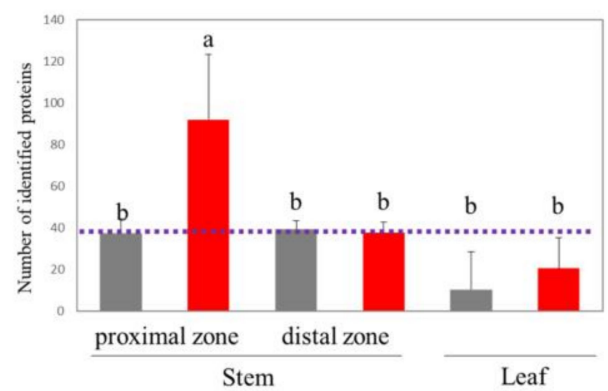

Figure 1. Stem inoculation as a model system to study Phytophthora cinnamomi infection on chestnut. (A) A schematic depiction of the experimental design. Two-year-old sweet chestnut saplings were stem wounded and subsequently inoculated with mycelium from P. cinnamomi mating type A2. Control plants received mock treatment. One week later, stem sections bordering the necrotic area (proximal zone) and around $20 \mathrm{~cm}$ upstream of it (distal zone) were harvested and used to extract total proteins and metabolites. (B) Number of high-scoring proteins assigned to the P. cinnamomi proteome in inoculated (red) and mock-treated (gray) chestnut saplings. Error bars represent standard deviation of at least three biological replicates. A false positive threshold corresponding to the maximal number of identified Phytophthora-like proteins in the mock-treated tissues is depicted by a dashed line. Different letters represent statistically significant differences according to Kruskal-Wallis test $(p<0.05)$. 
2.2. Phytophthora cinnamomi Infection Triggers Distinct Proteome Reprogramming Proximal to the Infection Site and Away from It

To get an insight into the molecular mechanisms that accompany the P. cinnamomi attack on chestnut, we assessed the global proteome changes in inoculated stems. To achieve a spatial resolution in understanding the infection process, we collected samples immediately bordering the necrotic site and approximately $20 \mathrm{~cm}$ upstream of it. The chestnut (Castanea sativa) genome had not been sequenced yet, so we used the genomes of the closely related Castanea species, $C$. dentata and C. mollissima, for peptide sequence annotation and protein identification [32,33]. Four hundred and thirteen proteins accumulated in the stem section proximal to the infection site, whereas the abundances of 228 proteins decreased upon P. cinnamomi infection according to a cut-off of $|\mathrm{FC}| \geq 2$ and $p \leq 0.05$ (Figure 2A). A similar number of proteins were differentially regulated (387 up and 296 down) distantly from the infection site.

A

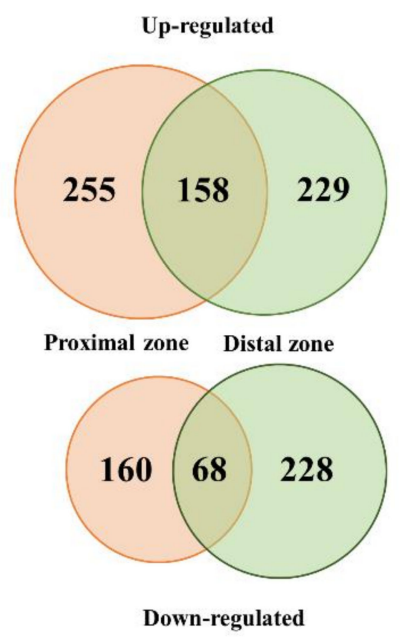

B

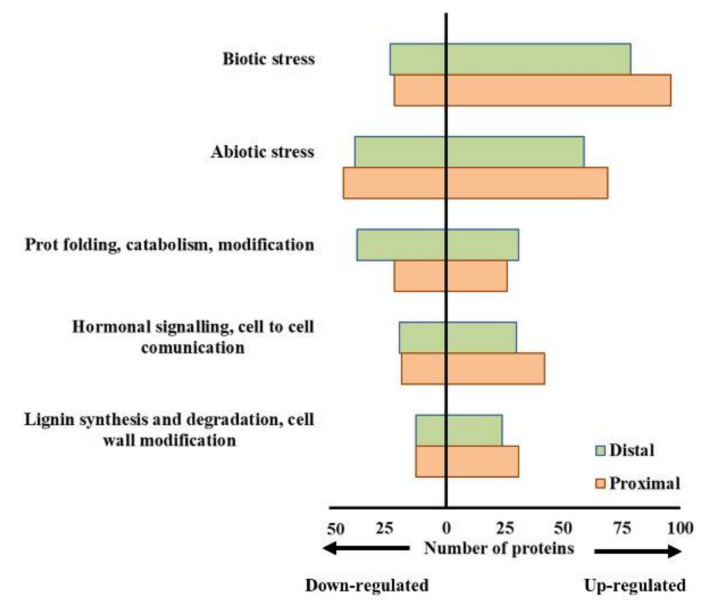

Figure 2. Proteome rearrangement in chestnut stems infected with Phytophthora cinnamomi. (A) Venn diagrams depicting the overlap between proteins that accumulated (upper panel) or decreased (lower panel) in stem sections proximal and distal to the infection zone in comparison to mock-treated controls $(|\mathrm{FC}| \geq 2, p \leq 0.05)$. (B) Top five most represented functional categories of differentially abundant proteins in proximal and distal stem sections upon P. cinnamomi attack. Bars represent number of accumulated (right side) or decreased (left side) proteins. Proteins were assigned to each functional category based on their putative Arabidopsis orthologs identified using the Uniprot database.

To make use of the available bioinformatics tools for functional enrichment, none of which contained Castanea-specific information, we queried the obtained protein sequences against the Arabidopsis thaliana proteome in order to identify orthologous proteins that were used for downstream analysis (Table S1). The majority of differentially abundant proteins isolated from both the proximal and distal stem sections were associated with biotic stress responses, followed by abiotic stress (Figure 2B). Their numbers were higher in the proximal zone, indicating a more pronounced response to P. cinnamomi attack. Similarly, more proteins associated with hormonal signaling and cell wall modification accumulated in the zone neighboring the necrotic area. Functional enrichment analysis of the proteins that uniquely accumulated in the stem section proximal to the infection site identified, among others, lignin metabolic process, L-phenylalanine metabolic process, and host programmed cell death (Figure 3). Proteins orthologous to cinnamyl alcohol dehydrogenase (CAD) 7 and 9 from Arabidopsis, for example, were specifically induced upon infection only in the proximal zone. CADs are important players in structural lignification during devolvement but are also strongly induced upon pathogen attack, leading to localized lignification [34]. Interestingly, CAD9 has been shown to be a target of multiple Phytophthora Avr3a-like effectors [35]. An ortholog of the Arabidopsis senescence 
marker SENESCENCE-ASSOCIATED GENE 21 (SAG21) also accumulated exclusively in the stem section bordering the infection zone. Two proteins orthologous to the Arabidopsis phenylalanine biosynthetic enzymes, arogenate dehydratase 6 and phenylalanine ammonia-lyase 2 (PAL2), were also induced upon infection only in the proximal zone. One hundred and fifty-eight proteins were commonly induced in the stem sections proximal and distal to the necrotic area (Figure 3). Among the functional categories that were overrepresented in this protein list were oxylipin biosynthetic process, defense response during incompatible interaction, lignin biosynthetic process, and response to jasmonic acid (JA). Moreover, a protein orthologous to the Arabidopsis 1-aminocyclopropane-1-carboxylic acid oxidase (ACO), involved in ethylene (ET) biosynthesis, accumulated in both stem sections. Similarly, an ortholog of PATHOGENESIS-RELATED 1 (PR1), a widely accepted molecular marker for salicylic acid (SA)-mediated signaling, was induced proximally and distally from the infection site implying that the presence of $P$. cinnamomi triggers partially overlapping defense responses in both stem sections. The top four overrepresented functional categories assigned to the proteins exclusively induced in the distal stem section were response to heat, amino acid catabolic process, translational initiation factor activity, and response to hypoxia (Figure 3).

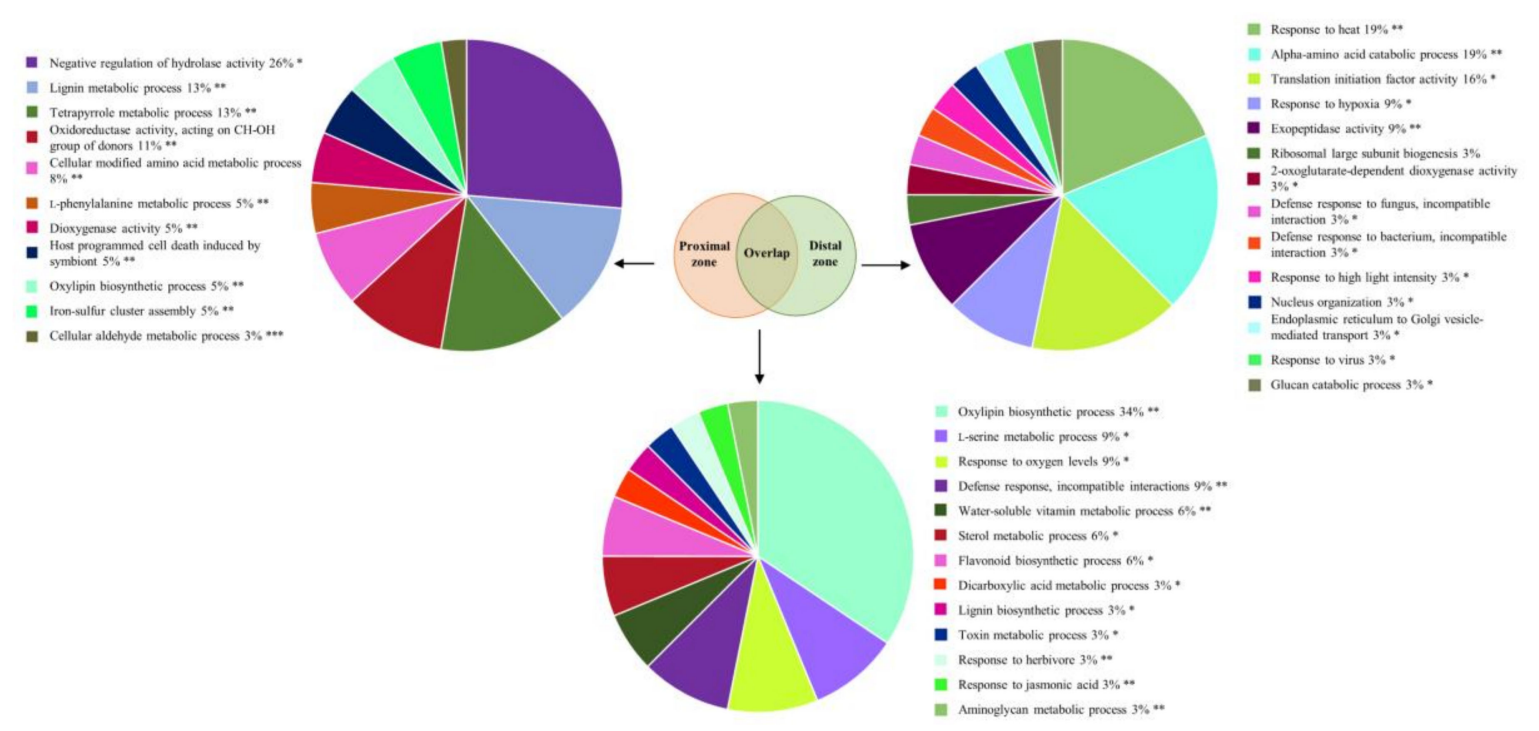

Figure 3. Functional annotation enrichment of proteins that accumulated in chestnut stem after Phytophthora cinnamomi infection. Pie charts depict functional categories assigned by the Cytoscape ClueGO plug-in using Arabidopsis orthologs of chestnut proteins that accumulated exclusively in stem sections proximal (left panel) and distal (right panel) to the infection site or were similarly induced in both sections (lower panel). Numbers indicate percentage of terms per group and asterisks indicate group $p$-value $\left(^{*} p<0.05 ;{ }^{* *} p<0.01 ;{ }^{* *} p<0.005\right)$.

The most overrepresented functional category of all proteins that decreased exclusively in stem sections proximal to the infection site was hydrogen peroxide metabolic process (Figure 4). It contained, among others, proteins orthologous to the Arabidopsis peroxidase 53 and peroxidase superfamily protein. Starch metabolism was similarly overrepresented with glucose-1-phosphate adenylyltransferase and beta-glucosidase 17 and 44 being decreased uniquely in the proximity of the infection site. Two hundred and twenty-eight proteins exclusively decreased in stem sections distant from the infection site. Among the functional categories that were overrepresented in this protein list were the polysaccharide metabolic process and polysaccharide localization (Figure 4). In particular, proteins orthologous to Arabidopsis granule-bound starch synthase 1, isoamylase 3, and alpha amylase-like protein were identified. Interestingly, response to heat was the second most overrepresented category in stem sections both proximal and distal to the infection site, but the specific proteins, which included mainly members of the chaperone and heat-shock protein (HSP) families, were largely different in each stem section. 


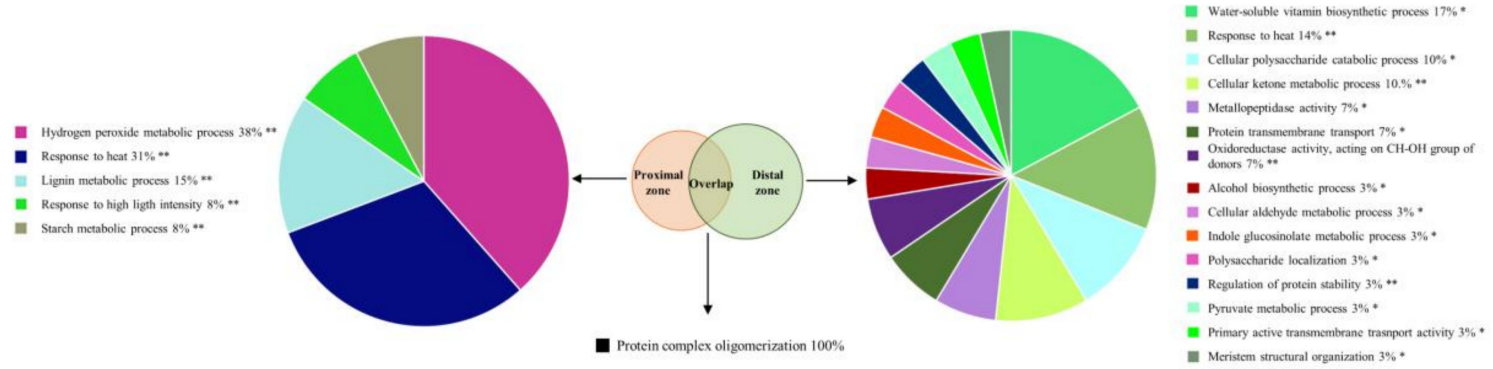

Figure 4. Functional annotation enrichment of proteins that decreased in chestnut stem after Phytophthora cinnamomi infection. Pie charts depict functional categories assigned by the Cytoscape ClueGO plug-in using Arabidopsis orthologs of chestnut proteins that decreased exclusively in stem sections proximal (left panel) and distal (right panel) to the infection site or similarly decreased in both sections (lower panel). Numbers indicate percentage of terms per group and asterisks indicate group $p$-value (* $p<0.05$; ${ }^{* *} p<0.01$ ).

A number of proteins showed a contrasting response in the stem sections proximal and distal to P. cinnamomi infection (Table 1). For example, an ortholog of the Arabidopsis universal stress protein PHOS32-like, which in Arabidopsis is phosphorylated after P. infestans elicitation [36], accumulated in the vicinity of the necrotic area, but its abundance decreased away from it. A similar expression pattern was observed for a protein orthologous to Arabidopsis SENSESCENCE-RELATED GENE 1 (SRG1)-like, which is highly induced during senescence [37]. Two vesicle transport-related proteins orthologous to Arabidopsis VESICLE TRANSPORT V-SNARE 13-LIKE and VESICLE-ASSOCIATED PROTEIN 2-1 also increased close to the infection site but decreased in the stem section distal to it. Proteins involved in exocytotic vesicle trafficking are often targeted by Phytophthora effectors and appear to be susceptibility factors [38]. Taken together, our results reveal a significant rearrangement of the proteome in both proximal and distal stem sections following P. cinnamomi infection. The responses of both tissue types shared similarities, but at the same time displayed distinct differences reflecting their spatial position in relation to the infection.

\subsection{The Stress-Related Amino Acid Proline Accumulates upon Phytophthora cinnamomi Infection}

The significant impact of the P. cinnamomi attack on the plant proteome prompted us to investigate how the infection process is reflected at the metabolite level. To this end, we quantified the steady-state levels of primary polar metabolites (mainly amino acids, sugars, and organic acids) in stem sections proximal and distal to the necrotic area resulting from P. cinnamomi infection. Most of the identified metabolites were either not affected by the presence of $P$. cinnamomi or responded similarly in both proximal and distal stem sections (Figure 5, Table S2). Among the metabolites that displayed a differential response upon infection were the stress-related amino acid proline and $\gamma$-aminobutyric acid (GABA) which modulate plant tolerance to abiotic and biotic stresses [39,40]. Both of them accumulated exclusively in the stem section proximal to the infection. A similar distribution pattern was observed for gallic acid. In contrast, the content of the amino aspartate, which is among the major nitrogen storage forms, was more negatively affected in the vicinity of the necrotic site. Accumulation of shikimic and cinnamic acid was detected in stem sections both proximal and distal to the infection site. The flavonoid D-catechin, on the other hand, accumulated close to the infection site only.

\subsection{Phytophthora cinnamomi Attack is Accompanied with Perturbation of Plant Hormonal Homeostasis}

Defense responses against pathogens are governed by hormonal signaling pathways with induction of SA signaling being associated predominantly with biotrophic interactions, whereas JA-related signal transduction pathways are mainly involved in necrotrophic interactions and insect infestation [41]. To assess the impact of P. cinnamomi on plant hormonal levels, we quantified SA and JA content in stem sections proximal and distal to the infection site. P. cinnamomi infection significantly increased SA 
levels in both stem sections (Figure 6A). Similarly, enhanced JA levels were observed both locally and distally in relation to the necrotic zone (Figure 6B). These results indicate that P. cinnamomi infection has a significant impact on plant hormonal homeostasis which likely modulates stress signaling pathways.

Table 1. Proteins oppositely regulated upon Phytophthora cinnamomi attack in stem sections proximal and distal to the infection zone $(|F C| \geq 2$ and $p \leq 0.05)$. Protein identities were assigned based on sequence homology to Quercus suber and Arabidopsis thaliana proteins.

\begin{tabular}{ccc}
\hline Protein Annotation & Proximal Zone & Distal Zone \\
\hline aconitate hydratase, cytoplasmic-like & $\mathrm{Up}$ & Down \\
alpha-amylase-like & $\mathrm{Up}$ & Down \\
aminoacylase-1 isoform X2 & $\mathrm{Up}$ & Down \\
beta-glucosidase 13-like & Down & $\mathrm{Up}$ \\
callose synthase 2-like & Down & $\mathrm{Up}$ \\
dehydrin Xero 1-like & $\mathrm{Up}$ & Down \\
DNA damage-binding protein 1a & Down & $\mathrm{Up}$ \\
exocyst complex component EXO70B1-like & $\mathrm{Up}$ & Down \\
Glu S.griseus protease inhibitor-like & $\mathrm{Up}$ & Down \\
lachrymatory-factor synthase-like & Down & $\mathrm{Up}$ \\
mannosyl-oligosaccharide glucosidase GCS1 & $\mathrm{Up}$ & Down \\
probable (S)-N-methylcoclaurine 3'-hydroxylase isozyme 2 & $\mathrm{Up}$ & Down \\
probable low-specificity L-threonine aldolase 1 isoform X2 & $\mathrm{Up}$ & Down \\
probable prolyl 4-hydroxylase 7 & $\mathrm{Up}$ & Down \\
protein disulfide isomerase pTAC5, chloroplastic & Down & Up \\
protein DJ-1 homolog B & $\mathrm{Up}$ & Down \\
protein KTI12 homolog isoform X2 & $\mathrm{Up}$ & Down \\
protein SRG1-like & $\mathrm{Up}$ & Down \\
vewn & $\mathrm{Up}$ & Down \\
vesicle-associated protein 2-1 & Down & Up \\
RNA-binding protein CP31B, chloroplastic-like & $\mathrm{Up}$ & Down \\
secoisolariciresinol dehydrogenase-like & Down & Up \\
small heat shock protein, chloroplastic-like & $\mathrm{Up}$ & Down \\
universal stress protein PHOS32-like & $\mathrm{Up}$ & Down \\
vesicle transport v-SNARE 13-like & $\mathrm{Up}$ & Down \\
\hline
\end{tabular}

\subsection{Phenylpropanoid Biosynthesis Pathway is Enriched following P. Cinnamomi Infection}

To pinpoint with higher evidence the pathways underlying P. cinnamomi pathogenicity on chestnut, we mapped proteins significantly altered upon infection together with significant metabolites to metabolic pathways for functional enrichment and pathway topology analysis using the "Joint Pathway Analysis" tool implemented in MetaboAnalyst 4.0 [42]. The pathways with the highest impact in the stem section proximal to the infection site were phenylpropanoid biosynthesis; phenylalanine, tyrosine, and tryptophan biosynthesis; galactose metabolism; alanine, aspartate, and glutamate metabolism; and TCA cycle (Figure 7A). Phenylpropanoid biosynthesis had a similar high impact upstream from the infection site together with synthesis and degradation of ketone bodies, starch, and sucrose metabolism, and TCA cycle (Figure 7B). Among the enzymes from the phenylpropanoid biosynthesis, a protein orthologous to Arabidopsis caffeoyl-CoA O-methyltransferase 1 accumulated in stem sections proximal to the inoculation site, whereas orthologs of feruloyl CoA ortho-hydroxylase 1 and caffeic acid 3-O-methyltrasnferase 1 accumulated both in the vicinity of the inoculation site and upstream of it.

\subsection{P. Cinnamomi Infection Alters the Chestnut Leaf Proteome and Metabolome}

Plants utilize long-distance signaling cascades to transmit information about pathogen attack and prepare distant tissues for subsequent invasion and/or alter their whole plant physiology that can ultimately affect their response to a broader range of biotic or abiotic stresses [43]. To assess whether information about P. cinnamomi infection is relayed to distant plant tissues, we probed the leaf 
proteomic and metabolomic profiles of infected chestnut saplings. One hundred and fifty-four proteins accumulated, whereas the abundance of 194 proteins decreased in comparison to leaves collected from mock-treated saplings ( $|\mathrm{FC}| \geq 2$ and $p \leq 0.05$; Figure $8 \mathrm{~A}$; Table S1). In contrast to the many proteins that could be attributed to biotic and abiotic stress responses found in the infected stems, no stress-related functional categories were observed in the leaves (Figure 8B).

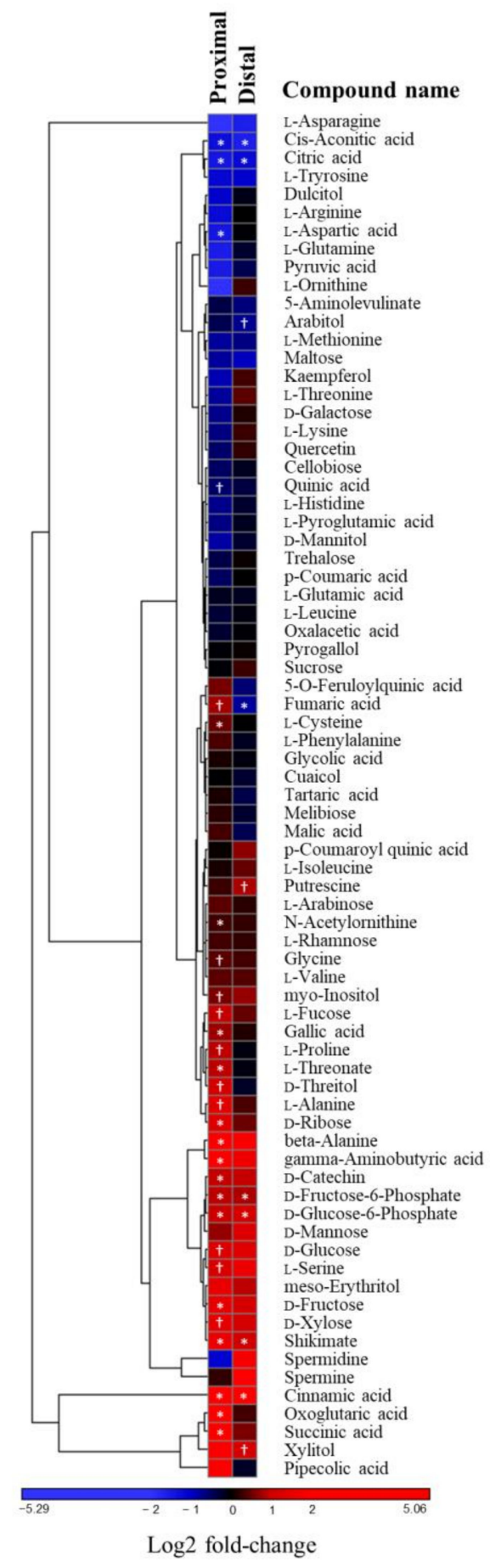

Figure 5. Effect of Phytophthora cinnamomi attack on chestnut metabolism. Heatmap showing changes in metabolites isolated from chestnut stem sections proximal and distal to the necrotic area seven days after P. cinnamomi inoculation relative to mock-treated controls. Symbols indicate statistically significant differences according to Student's $t$-test $(p<0.1+$ and $p<0.05 *)$. 

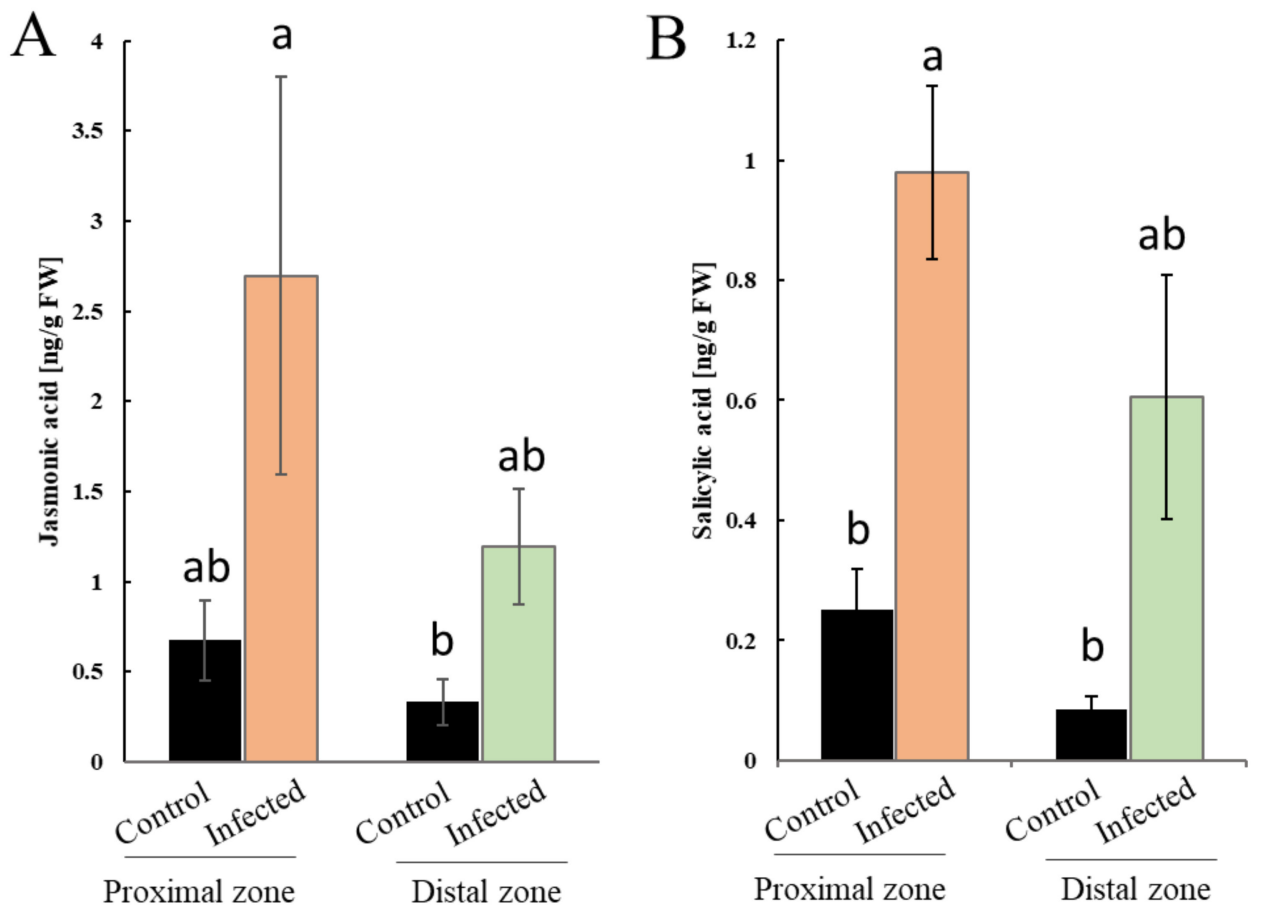

Figure 6. Effect of P. cinnamomi infection on plant hormonal levels. (A) Jasmonic acid content in stem sections proximal (orange) and distal (green) to the necrotic area seven days after P. cinnamomi inoculation in comparison to mock-treated controls (black). (B) Salicylic acid content in stem sections proximal (orange) and distal (green) to the necrotic area seven days after P. cinnamomi inoculation in comparison to mock-treated controls (black). Bars represent averages of four biological replicates \pm SE. Different letters depict statistical differences according to one-way analysis of variance (ANOVA) with Tukey's post hoc test $(p<0.05)$.

A

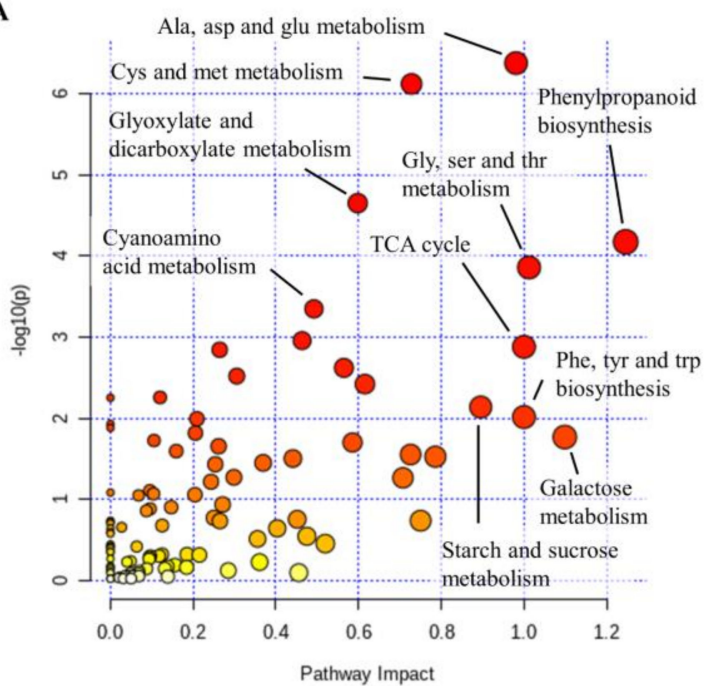

B

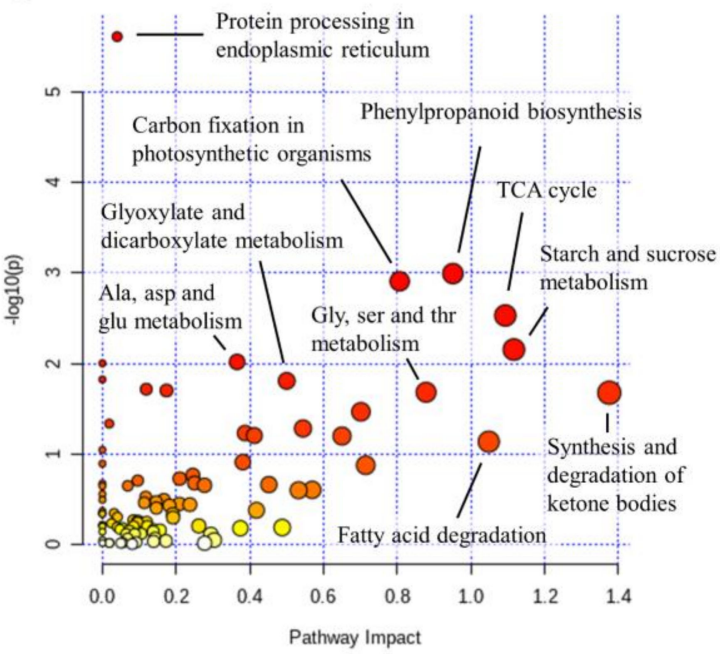

Figure 7. Functional enrichment and pathway topology analysis of proteins and metabolites affected in chestnut stem upon Phytophthora cinnamomi stem inoculation. (A) Integrated metabolic pathway analysis of proteins and metabolites differentially regulated in stem sections proximal to the necrotic zone seven days after P. cinnamomi inoculation performed using the "Joint Pathway Analysis" tool implemented in MetaboAnalyst 4.0. (B) Integrated metabolic pathway analysis of proteins and metabolites differentially regulated in stem sections distal to the necrotic zone seven days after P. cinnamomi inoculation performed using the "Joint Pathway Analysis" tool implemented in MetaboAnalyst 4.0. 
A

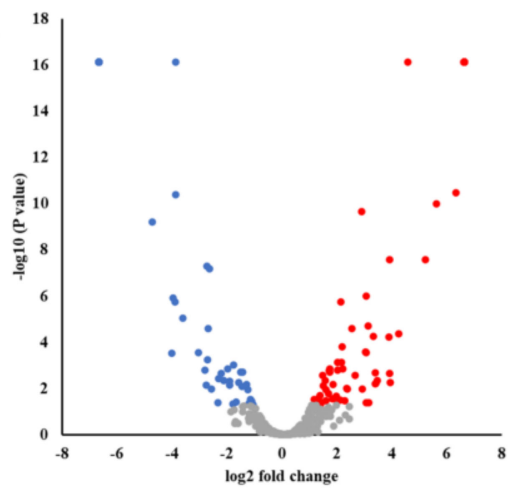

B

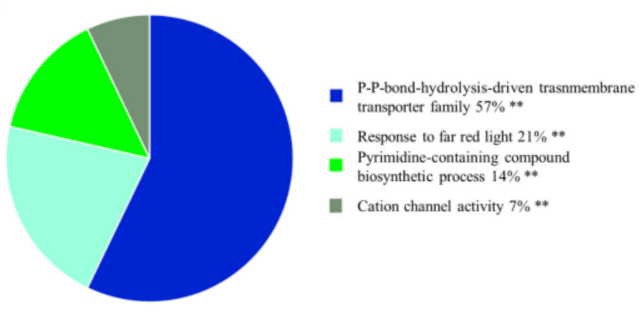

C
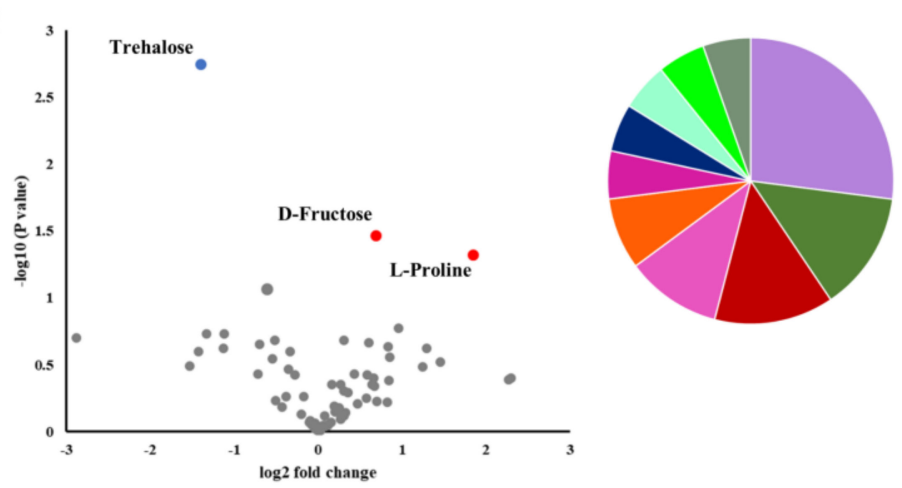

[Nesponse to oxygen levels $18 \%$

- Glucan catabolic process $18 \%$ *

- Antibiotic catabolic process $18 \% * *$

- Response to topologically incorrect protein $12 \%$ *

- Protein-containing complex disassembly $6 \% *$

- Cell wall macromolecule catabolic process $6 \%$ **

- Endoplasmic reticulum to Golgi vesicle-mediated transport $6 \%$ **

Chaperone-mediated protein folding $6 \%$ *

- Carbohydrate phosphorylation $6 \%$ *

E Pyruvate metabolic process $6 \%$ *

Figure 8. Effect of Phytophthora cinnamomi stem infection on chestnut leaf proteome and metabolome. (A) Volcano plot of proteins upregulated (red) and downregulated (blue) in chestnut leaves seven days after stem inoculation with P. cinnamomi ( $\log 2 \mathrm{FC} \geq 1$ and $p \leq 0.05)$. (B) Functional enrichment analysis based on Arabidopsis orthologs of chestnut proteins that accumulated (upper panel) or decreased (lower panel) in leaves of P. cinnamomi-inoculated chestnut plants after seven days performed using Cytoscape ClueGO plug-in. Numbers indicate percentage of terms per group and asterisks indicate group $p$-value $\left({ }^{*} p<0.05 ;{ }^{* *} p<0.01\right)$. (C) Volcano plot of the leaf metabolites with increased (red) and decreased (blue) concentration seven days after stem inoculation with P. cinnamomi ( $p$ value $\leq 0.05$ ).

Similarly, the metabolomic profile of leaves from infected saplings was markedly different from that of stem sections proximal and distal to the necrotic zone. A limited number of metabolites accumulated (2) or decreased (1) following infection (Figure 8C, Table S2). Despite the limited overlap between the metabolic changes in leaves and stem sections, proline increase was also observed in leaves of infected saplings. Taken together, these results indicate that $P$. cinnamomi infection also impacts the leaf proteome and metabolome.

\section{Discussion}

In this study, we characterized the susceptible interaction between the invasive oomycete Phytophthora cinnamomi and one of its economically important hosts Castanea sativa. By integrating proteomic and metabolomic profiling and targeted hormonal analysis, we revealed a major molecular impact of P. cinnamomi attack on sweet chestnut.

\subsection{P. Cinnamomi Inoculation Triggers a Defense Response Common to Abiotic Stress}

P. cinnamomi is a soil-borne pathogen that causes root rot (ink disease) and eventually tree death $[5,10]$. However, despite being mainly a root pathogen, P. cinnamomi can also infect trunks and stems directly. Stem inoculation is accompanied with phloem necrosis and xylem blocking that ultimately leads to perturbation of plant water relations [44]. As a result, the response against Phytophthora shares many similarities with drought stress and leads to negative effects on photosynthesis and photooxidative damage. In fact, eucalyptus trees display a marked water stress-response following 
stem inoculation with P. cinnamomi [17]. Numerous proteins implicated in abiotic stress responses accumulated in the stem of infected plants, supporting the idea that the P. cinnamomi attack negatively perturbs plant physiology. Moreover, we observed accumulation of proline in stem sections bordering the infection zone and in leaves of infected saplings, indicating altered water potential that is likely due to blocked vasculature. The role of proline during stress responses has been attributed to its osmolite properties and antioxidant characteristics. Proline accumulation has also been shown to modulate programmed cell death during plant-pathogen interactions, implying that its role upon P. cinnamomi attack might extend beyond its osmolite properties [45].

\subsection{Manipulation of Plant Defense by P. Cinnamomi}

Several heat-shock proteins (HSPs) which normally accumulate under diverse abiotic stress conditions [46] were repressed following P. cinnamomi infection in the stem sections proximal and distal to the necrotic zone. Apart from their role in abiotic stress, HSPs are important players in defense signaling during pathogen attacks by modulating the stability and accumulation of resistance proteins [47]. Silencing of small HSPs has been linked to a decrease in the expression of defense-related genes, such as PR1 and PR4 in tobacco, and the perturbation of SA signaling [48]. Interestingly, HSPs are prime targets for effector proteins from Phytophthora which leads to increased pathogen virulence [49,50]. Further confirming the important role of HSPs in response to pathogens is the fact that Phytophthora species have been shown to decrease the levels of host HSPs by targeting their promoters [44].

\subsection{SA-Mediated Defense Signaling Pathways Are Activated upon P. Cinnamomi Attack}

SA signaling plays a crucial role in the defense against biotrophic pathogens and establishment of a hypersensitive response (HR). The importance of SA signaling is not limited to plant-biotroph interactions, but has been also reported in defense against sucking insects and hemibiotrophs [51]. Contrasting evidence exists about the role of SA signaling during Phytophthora infection. Whereas SA-pretreatment on rubber tree reduced the disease symptoms against P. palmivora [52], P. cinnamomi attack on chestnut did not alter SA levels [53]. Interestingly, we detected increased SA levels in stem sections both proximal and distal to the infection (Figure 6B), indicating that P. cinnamomi mounts a defense response similar to that triggered by biotrophic pathogens. Further corroborating this observation was the accumulation of proteins from the phenylalanine ammonia-lyase (PAL) pathway and cinnamic acid, an intermediate in the PAL pathway. SA can be synthesized via the isochorismate synthase and PAL pathway, and the importance of both pathways can vary between species and conditions [54]. Activation of SA signaling upon Phytophthora infection is believed to modulate $\mathrm{H}_{2} \mathrm{O}_{2}$ content and antioxidant enzyme levels, and impact lignin deposition $[52,55,56]$.

Induction of SA synthesis during pathogen attack has been correlated with upregulation of the flavan-3-ol pathway, and particularly with increases in catechin levels [57]. Flavan-3-ols are part of the constitutive and induced chemical defense against fungal pathogens in woody plants that could inhibit spore germination and prevent hyphal growth $[58,59]$. The accumulation of $\mathrm{D}$-catechin observed in Phytophthora-infected chestnut stems, together with the increase of gallic acid required for biosynthesis of their gallate conjugates, indicates that similar defense mechanisms can be deployed against oomycetes.

\subsection{Activation of JA Signaling upon P. Cinnamomi Attack Likely Plays Multiple Roles during Infection}

JA signaling fuels the accumulation of diverse defense compounds in various plant species, including Castanea, and promotes resistance to necrotrophic pathogens and chewing insects [60,61]. JA and its biologically active conjugate JA-Ile have been described to increase in P. cinnamomi-infected roots of both susceptible and resistant Castanea clones [53]. We observed accumulation of several JA biosynthetic enzymes, such as allene oxide synthase and linoleate 13S-lipoxygenase, which was accompanied with increased JA content in stem sections proximal and distal to the infection zone (Figure 6). Moreover, other linolenic acid-derived oxylipins have been reported to play a direct role 
in oomycete infection by displaying antifungal activities and have been proposed to be important components of plant defense against Phytophthora [62,63]. Proteins related to the oxylipin biosynthetic process were overrepresented in chestnut stems infected with P. cinnamomi (Figure 3). Taken together, our results indicate that activation of JA signaling accompanies $P$. cinnamomi attack on chestnut.

JA signaling has been shown to modulate sugar metabolism during the interaction between soybean and P. sojae via increase in extracellular invertases activity [64]. We observed accumulation of several sugars including glucose and fructose in Phytophthora-infected chestnut stems (Figure 5). Sugars are involved in plant defense as substrates for several secondary metabolites, including the building blocks of lignin [65]. Furthermore, soluble hexoses have been shown to activate genes related to the shikimate pathway [66]. The accumulation of sugars close to the infection site, however, is not always beneficial, as the pathogen can use them for its own benefit [67]. Moreover, some pathogens have developed mechanisms to hijack host carbohydrate metabolism $[67,68]$.

\subsection{Establishment of Physical Barriers is a Key Part of the Defense against P. Cinnamomi}

The phenylpropanoid pathway is a prominent feature of plant defense against pathogens, which tends to be upregulated in resistant lines [69]. This pathway generates precursors for the localized biosynthesis of lignin and suberin, which can be used to establish physical barriers and prevent pathogen spreading [70]. Shikimic and cinnamic acid, precursors of the phenylpropanoid biosynthetic pathway, accumulated in chestnut stems after P. cinnamomi infection (Figure 5). Additionally, several proteins related to phenylpropanoid and lignin biosynthesis, such as peroxidases, S-adenosylmethionine synthases, and CADs, were upregulated in both stem sections (Figure 2B). Phenylpropanoids also exhibit a broad-spectrum antimicrobial activity and have been associated with plant hypersensitive response [70]. Furthermore, CADs could also contribute to the defense against $P$. cinnamomi by reducing Phytophthora aldehyde aromatic effectors into alcohols, and thus inactivating them [71].

Flavonoids have been suggested to promote callus and tylose formation and closure of vascular tissue to prevent pathogen expansion [72]. Additionally, flavonoid glycosides can form a hard and crystalline structure that blocks the path of the pathogen and cannot be broken by cell wall degrading enzymes [73]. Flavonoids are synthesized via the phenylpropanoid pathway which was overrepresented in infected stems. Specifically, we observed accumulation of proteins orthologous to Arabidopsis feruloyl CoA ortho-hydroxylase 1 and flavone 3'-O-methyltransferase 1 next to the infection site, implying that flavonoids can play a role in the interaction between Phytophthora and chestnut.

Proteins involved in vesicle trafficking seem to be key susceptibility factors during early pathogen establishment [38]. Interestingly, we observed accumulation of V-SNARE and VAMP family proteins close to the infection site, but decreasing concentrations upstream of it (Table 1). Proteins from those families have been suggested to mediate pre-invasion resistance, ETI response, and participate in the secretion of anti-microbial proteins [26,27]. They are also thought to be involved in post-invasive defense by carrying resistance proteins to the extrahaustorial membrane [74]. We also observed accumulation of proteins secreted into the extracellular space, such as osmotins (OSMOTIN 34 and OSMOTIN-LIKE proteins), endochitinases (basic endochitinase B and endochitinase EP), and pectinesterases (PECTINESTERASE 2-LIKE). Osmotins can inhibit hyphal growth by increasing the permeability of the pathogen membrane and thus impairing their ability to maintain a $\mathrm{pH}$ gradient [75], while endochitinases and pectinesterases are cell wall degrading enzymes that can damage the pathogen without harming the host $[76,77]$. Additionally, pectinesterases are also involved in the reinforcement of a host's own cell wall by calcium-pectate gel apposition, which has been associated with resistance to several Phytophthora species [78].

\subsection{Increase of Sugar Content in Chestnut Leaves after P. Cinnamomi Inoculation}

The molecular response observed in leaves of stem-infected chestnut saplings was markedly different to that observed in the stem and did not display a clear stress response signature. A marked exception was the accumulation of proline which could be attributed to the reduction in water uptake 
as a result of vasculature destruction during Phytophthora stem infection. Impaired phloem transport has also been linked to the accumulation of carbohydrates and starch in leaves of infected plants that could ultimately lead to photoinhibition of photosynthesis [15]. We detected accumulation of D-fructose, together with a decrease of several proteins related to starch degradation (Alpha-glucan phosphorylase, isoamylase 3, phosphoglycan, and water dikinase) suggesting that the P. cinnamomi attack on chestnut could also impact leaf sugar and starch levels.

\section{Materials and Methods}

\subsection{Plant Material}

Sweet chestnut (Castanea sativa) saplings were grown from seeds collected in a natural sweet chestnut forest in Serbia $\left(42^{\circ} 33^{\prime} 52^{\prime \prime} N\right.$; $21^{\circ} 50^{\prime} 58^{\prime \prime}$ E). Seeds were sown in 201 plastic boxes, containing an autoclaved mixture of peat, sand, and perlite (1/1/1) and grown under controlled conditions at $22-25^{\circ} \mathrm{C}$. Plants were watered twice per week until the soil reached field capacity.

\subsection{P. Cinnamomi Inoculation}

A Phytophthora cinnamomi isolate (TJ349) belonging to A2 mating type was selected from the Phytophthora Research Centre (www.phytophthora.org/) culture collection and developed on V8A media (prepared with $100 \mathrm{~mL} / \mathrm{l}$ of clarified V8 juice (Pfanner, Lauterach, Austria), $20 \mathrm{~g} / \mathrm{l}$ of agar (Sigma Aldrich, St. Louis, MO, USA), $2 \mathrm{~g} / \mathrm{l}$ of $\mathrm{CaCO}_{3}$, and $900 \mathrm{~mL} / \mathrm{l}$ of distilled water), and incubated for 5 days at $20^{\circ} \mathrm{C}$ in the dark. Inoculation of stems of two-year-old plants was performed using the under-bark stem inoculation test. Wounds were made using a metal cork borer of $6 \mathrm{~mm}$ in diameter at $5-7 \mathrm{~cm}$ from the ground level, sterilized in 70\% alcohol, and briefly burned over an open flame. From the growing edge of five-day-old colonies, pieces of agar with mycelium were taken with the same metal cork borer and plated with the mycelium side to exposed wood. Inoculation places were sealed with parafilm and with aluminum foil. Control plants received pieces of sterile agar.

\subsection{Sample Collection}

Stem sections ( $2 \mathrm{~cm}$ in length) were collected right at the end of the necrotic tissue and approximately $20 \mathrm{~cm}$ upstream of that area seven days after inoculation. The youngest fully developed leaf of each sapling was also harvested. Samples were flash-frozen in liquid nitrogen, ground to powder in a Retsch MM 400 mill (Retsch GmbH, Haan, Germany), and stored at $-80^{\circ} \mathrm{C}$ until analysis. Samples from a total of four plants per treatment were collected and processed.

\subsection{Shotgun Proteomics}

Total proteins were extracted as previously described using a combination of phenol/acetone/TCA [79]. Aliquots corresponding to $2.5 \mu \mathrm{g}$ of peptide were analyzed by nanoflow C18 reverse-phase liquid chromatography using a $15 \mathrm{~cm}$ column (Zorbax, Agilent), a Dionex Ultimate 3000 RSLC nano-UPLC system (Thermo Fisher Scientific, Waltham, MA, USA) and the Orbitrap Fusion Lumos Tribrid Mass Spectrometer (Thermo Fisher Scientific) as described previously [80]. The measured spectra were recalibrated and searched against the reference protein database by Proteome Discoverer 2.4, employing Sequest HT (Thermo Fisher Scientific) and MS Amanda 2.0 [81] with the following parameters: Enzyme - trypsin, max two missed cleavage sites; modifications-carbamidomethyl (Cys) and up to three dynamic modifications including met oxidation, Asn/Gln deamidation, N-terminal acetylation; MS1 tolerance-5 ppm (MS Amanda), 10 ppm (Sequest), MS2 tolerance-0.02 Da (MS Amanda), 0.1 Da (Sequest). Only proteins with at least two unique peptides were considered for quantitative analysis. The quantitative differences were determined by Minora, employing precursor ion quantification followed by normalization and background-based $t$-test. The mass spectrometry proteomics data have been deposited to the ProteomeXchange Consortium via the Proteomics Identification Database (PRIDE) [82] partner repository with the dataset identifier PXD022381. 


\subsection{Metabolite Profiling}

Polar metabolites were extracted as previously described with few modifications [83]. Samples were derivatized by $20 \mu \mathrm{L}$ of methoximation solution ( $40 \mathrm{mg}$ methoxyamine hydrochloride in $1 \mathrm{~mL}$ pyridine) and incubated for $90 \mathrm{~min}$ at $30^{\circ} \mathrm{C}$ with continuous shaking. After the incubation, $80 \mu \mathrm{L}$ of the silylation solution (N-methyl-N-(trimethylsilyl)trifluoroacetamide) was added and the mixture was incubated for $30 \mathrm{~min}$ at $37^{\circ} \mathrm{C}$ with continuous shaking. Samples for hormonal analyses were spiked with deuterated salicylic acid (2-hydroxy $\left[{ }^{2} \mathrm{H}_{4}\right]$ benzoic acid; Olchemim, CZ) and processed as described before [84]. Derivatized samples were measured using a Q Exactive GC Orbitrap GC-tandem mass spectrometer and Trace 1300 Gas chromatograph (Thermo Fisher Scientific, Waltham, MA, USA). Samples were injected using the split mode (inlet temperature $250{ }^{\circ} \mathrm{C}$, splitless time $0.8 \mathrm{~min}$, purge flow $5.0 \mathrm{~mL} / \mathrm{min}$, split flow $6.0 \mathrm{~mL} / \mathrm{min}$ ) onto a TG-5SILMS GC Column (Thermo Fisher, $30 \mathrm{~m} \times 0.25 \mathrm{~mm} \times 0.25 \mu \mathrm{m}$ ) with helium as a carrier gas at a constant flow of $1.2 \mathrm{~mL} / \mathrm{min}$. Metabolites were separated with a $28 \mathrm{~min}$ gradient $\left(70{ }^{\circ} \mathrm{C}\right.$ for 5 min followed by $9{ }^{\circ} \mathrm{C}$ per min gradient to $320^{\circ} \mathrm{C}$ and finally $10 \mathrm{~min}$ hold time) and ionized using the electron ionization mode (electron energy $70 \mathrm{eV}$, emission current $50 \mu \mathrm{A}$, transfer line and ion source temperature $250{ }^{\circ} \mathrm{C}$ ). The MS operated in the full scan mode, 60,000 resolution, scan range $50-750 \mathrm{~m} / \mathrm{z}$, automatic maximum allowed injection time with automatic gain control set to $1 \mathrm{e} 6$, and lock mass (m/z): 207.0323. Data were analyzed by TraceFinder 4.1 with Deconvolution Plugin 1.4 (Thermo) and searched against the NIST2014, GC-Orbitrap Metabolomics library, and in-house library. Only metabolites fulfilling identification criteria (score $\geq 75$ and $\Delta \mathrm{RI}<2 \%$ ) were included in the final list. The quantitative differences were determined by manual peak assignment in Skyline 20.1 [85], using the extracted ion chromatogram (2 ppm tolerance).

\subsection{Functional Annotation and Bioinformatics Analysis}

The identified protein sequences were queried against the SUBA (https://suba.live/) and NCBI (https://www.ncbi.nlm.nih.gov) databases to generate a list of Arabidopsis thaliana and Quercus suber homologs, respectively. Putative orthologs with the highest score were selected for downstream data analysis and interpretation. The Uniprot database (https://www.uniprot.org/) was used to assign each of the putative Arabidopsis homologs to functional categories. Gene ontology (GO) enrichment analysis was performed using the Cytoscape ClueGO plugin [86]. Functional enrichment and pathway topology analysis was performed using the "Joint Pathway Analysis" tool implemented in MetaboAnalyst 4.0 [42].

Supplementary Materials: Supplementary materials can be found at http://www.mdpi.com/1422-0067/21/22/ $8525 /$ s1.

Author Contributions: Conceptualization, I.M., M.T., M.Č., I.S.-F., M.B., P.K; methodology, I.M., M.Č.; formal analysis, P.K., I.S.-F, M.B.; writing-original draft preparation, P.K., I.S.-F., I.M., M.Č.; writing一review and editing, supervision, B.B., M.Č., P.K; funding acquisition, B.B, M.T. All authors have read and agreed to the published version of the manuscript.

Funding: This work was supported by the European Regional Development Fund, Project Phytophthora Research Centre Reg. No. CZ.02.1.01/0.0/0.0/15_003/0000453.

Acknowledgments: The authors would like to thank Thomas Jung for the insightful discussions and access to the resources of the Phytophthora Research Centre.

Conflicts of Interest: The authors declare no conflict of interest.

\section{References}

1. Robin, C.; Morel, O.; Vettraino, A.M.; Perlerou, C.; Diamandis, S.; Vannini, A. Genetic variation in susceptibility to Phytophthora Cambivora in European chestnut (Castanea sativa). For. Ecol. Manag. 2006, 226, 199-207. [CrossRef]

2. Tziros, G.T.; Diamandis, S. First report of Phytophthora cinnamomi causing ink disease on Castanea sativa in Greece. J. Plant Pathol. 2014, 96, 415-417. [CrossRef] 
3. Santos, C.; Machado, H.; Correia, I.; Gomes, F.; Gomes-Laranjo, J.; Costa, R. Phenotyping Castanea hybrids for Phytophthora cinnamomi resistance. Plant Pathol. 2015, 64, 901-910. [CrossRef]

4. Beakes, G.W.; Thines, M.; Honda, D. Straminipile "Fungi"-Taxonomy. In eLS; John Wiley \& Sons, Ltd.: Chichester, UK, 2015; pp. 1-9.

5. Jung, T.; Pérez-Sierra, A.; Durán, A.; Jung, M.H.; Balci, Y.; Scanu, B. Canker and decline diseases caused by soil- and airborne Phytophthora species in forests and woodlands. Pers. Mol. Phylogeny Evol. Fungi 2018, 40, 182-220. [CrossRef] [PubMed]

6. Erwin, D.C.; Ribeiro, O.K. Phytophthora Diseases Worldwide; APS Press: St. Paul, MN, USA, 1996.

7. Burgess, T.I.; Scott, J.K.; Mcdougall, K.L.; Stukely, M.J.C.; Crane, C.; Dunstan, W.A.; Brigg, F.; Andjic, V.; White, D.; Rudman, T.; et al. Current and projected global distribution of Phytophthora cinnamomi, one of the world's worst plant pathogens. Glob. Chang. Biol. 2017, 23, 1661-1674. [CrossRef] [PubMed]

8. Jung, T.; Jung, M.H.; Scanu, B.; Seress, D.; Kovács, G.M.; Maia, C.; Pérez-Sierra, A.; Chang, T.T.; Chandelier, A.; Heungens, K.; et al. Six new phytophthora species from ITS clade 7a including two sexually functional heterothallic hybrid species detected in natural ecosystems in Taiwan. Pers. Mol. Phylogeny Evol. Fungi 2017, 38, 100-135. [CrossRef]

9. Ribeiro, O.K. A historical perspective of Phytophthora. In Phytophthora: A Global Perspective; CABI: Wallingford, UK, 2013; pp. 1-10.

10. Vettraino, A.M.; Morel, O.; Perlerou, C.; Robin, C.; Diamandis, S.; Vannini, A. Occurrence and distribution of Phytophthora species in European chestnut stands, and their association with Ink Disease and crown decline. Eur. J. Plant Pathol. 2005, 111, 169-180. [CrossRef]

11. Khaliq, I.; Hardy, G.E.S.J.; Burgess, T.I. Phytophthora cinnamomi exhibits phenotypic plasticity in response to cold temperatures. Mycol. Prog. 2020, 19, 405-415. [CrossRef]

12. Zuluaga, A.P.; Vega-Arreguín, J.C.; Fei, Z.; Ponnala, L.; Lee, S.J.; Matas, A.J.; Patev, S.; Fry, W.E.; Rose, J.K.C. Transcriptional dynamics of Phytophthora infestans during sequential stages of hemibiotrophic infection of tomato. Mol. Plant Pathol. 2016, 17, 29-41. [CrossRef]

13. Hardham, A.R.; Blackman, L.M. Molecular cytology of Phytophthora-plant interactions. Australas. Plant Pathol. 2010, 39, 29-35. [CrossRef]

14. Attard, A.; Gourgues, M.; Callemeyn-Torre, N.; Keller, H. The immediate activation of defense responses in Arabidopsis roots is not sufficient to prevent Phytophthora parasitica infection. New Phytol. 2010, 187, 449-460. [CrossRef] [PubMed]

15. Oßwald, W.; Fleischmann, F.; Rigling, D.; Coelho, A.C.; Cravador, A.; Diez, J.; Dalio, R.J.; Horta Jung, M.; Pfanz, H.; Robin, C.; et al. Strategies of attack and defence in woody plant-Phytophthora interactions. For. Pathol. 2014, 44, 169-190. [CrossRef]

16. Wang, D.; Eyles, A.; Mandich, D.; Bonello, P. Systemic aspects of host-pathogen interactions in Austrian pine (Pinus nigra): A proteomics approach. Physiol. Mol. Plant Pathol. 2006, 68, 149-157. [CrossRef]

17. Meyer, F.E.; Shuey, L.S.; Naidoo, S.; Mamni, T.; Berger, D.K.; Myburg, A.A.; van den Berg, N.; Naidoo, S. Dual RNA-sequencing of Eucalyptus nitens during Phytophthora cinnamomi challenge reveals pathogen and host factors influencing compatibility. Front. Plant Sci. 2016, 7, 191. [CrossRef]

18. Conrad, A.O.; Rodriguez-Saona, L.E.; McPherson, B.A.; Wood, D.L.; Bonello, P. Identification of Quercus agrifolia (coast live oak) resistant to the invasive pathogen Phytophthora ramorum in native stands using Fourier-transform infrared (FT-IR) spectroscopy. Front. Plant Sci. 2014, 5, 521. [CrossRef] [PubMed]

19. Dodd, R.S.; Hüberli, D.; Mayer, W.; Harnik, T.Y.; Afzal-Rafii, Z.; Garbelotto, M. Evidence for the role of synchronicity between host phenology and pathogen activity in the distribution of sudden oak death canker disease. New Phytol. 2008, 179, 505-514. [CrossRef]

20. Giesbrecht, M.B.; Hansen, E.M.; Kitin, P. Histology of Phytophthora Ramorum in Notholithocarpus Densiflorus Bark Tissues. N. Z. J. For. Sci. 2011, 41, S89-S100.

21. Clemenz, C.; Fleischmann, F.; Häberle, K.H.; Matyssek, R.; Oßwald, W. Photosynthetic and leaf water potential responses of Alnus glutinosa saplings to stem-base inoculaton with Phytophthora alni subsp. alni. Tree Physiol. 2008, 28, 1703-1711. [CrossRef]

22. Doughari, J.H. An Overview of Plant Immunity. J. Plant Pathol. Microbiol. 2015, 6, 1-11. [CrossRef]

23. Han, X.; Kahmann, R. Manipulation of phytohormone pathways by effectors of filamentous plant pathogens. Front. Plant Sci. 2019, 10, 822. [CrossRef] 
24. Lo Presti, L.; Lanver, D.; Schweizer, G.; Tanaka, S.; Liang, L.; Tollot, M.; Zuccaro, A.; Reissmann, S.; Kahmann, R. Fungal Effectors and Plant Susceptibility. Annu. Rev. Plant Biol. 2015, 66, 513-545. [CrossRef] [PubMed]

25. Kamoun, S. A catalogue of the effector secretome of plant pathogenic oomycetes. Annu. Rev. Phytopathol. 2006, 44, 41-60. [CrossRef] [PubMed]

26. Kalde, M.; Nühse, T.S.; Findlay, K.; Peck, S.C. The syntaxin SYP132 contributes to plant resistance against bacteria and secretion of pathogenesis-related protein 1. Proc. Natl. Acad. Sci. USA 2007, 104, 11850-11855. [CrossRef] [PubMed]

27. Leborgne-Castel, N.; Bouhidel, K. Plasma membrane protein trafficking in plant-microbe interactions: A plant cell point of view. Front. Plant Sci. 2014, 5, 735. [CrossRef] [PubMed]

28. dit Frey, N.F.; Robatzek, S. Trafficking vesicles: Pro or contra pathogens? Curr. Opin. Plant Biol. 2009, 12, 437-443. [CrossRef]

29. Teh, O.K.; Hofius, D. Membrane trafficking and autophagy in pathogen-triggered cell death and immunity. J. Exp. Bot. 2014, 65, 1297-1312. [CrossRef] [PubMed]

30. Bozkurt, T.O.; Schornack, S.; Win, J.; Shindo, T.; Ilyas, M.; Oliva, R.; Cano, L.M.; Jones, A.M.E.; Huitema, E.; Van Der Hoorn, R.A.L.; et al. Phytophthora infestans effector AVRblb2 prevents secretion of a plant immune protease at the haustorial interface. Proc. Natl. Acad. Sci. USA 2011, 108, 20832-20837. [CrossRef]

31. Chanclud, E.; Morel, J.B. Plant hormones: A fungal point of view. Mol. Plant Pathol. 2016, 17, $1289-1297$. [CrossRef]

32. Barakat, A.; Diloreto, D.S.; Zhang, Y.; Smith, C.; Baier, K.; Powell, W.A.; Wheeler, N.; Sederoff, R. Comparison of the transcriptomes of American chestnut (Castanea dentata) and Chinese chestnut (Castanea mollissima) in response to the chestnut blight infection. BMC Plant Biol. 2009, 9, 1-11. [CrossRef]

33. Staton, M.; Zhebentyayeva, T.; Olukolu, B.; Fang, G.C.; Nelson, D.; Carlson, J.E.; Abbott, A.G. Substantial genome synteny preservation among woody angiosperm species: Comparative genomics of Chinese chestnut (Castanea mollissima) and plant reference genomes. BMC Genom. 2015, 16, 744. [CrossRef]

34. Preisner, M.; Wojtasik, W.; Kostyn, K.; Boba, A.; Czuj, T.; Szopa, J.; Kulma, A. The cinnamyl alcohol dehydrogenase family in flax: Differentiation during plant growth and under stress conditions. J. Plant Physiol. 2018, 221, 132-143. [CrossRef] [PubMed]

35. Li, T.; Wang, Q.; Feng, R.; Li, L.; Ding, L.; Fan, G.; Li, W.; Du, Y.; Zhang, M.; Huang, G.; et al. Negative regulators of plant immunity derived from cinnamyl alcohol dehydrogenases are targeted by multiple Phytophthora Avr3a-like effectors. New Phytol. 2019. [CrossRef] [PubMed]

36. Lenman, M.; Sörensson, C.; Andreasson, E. Enrichment of phosphoproteins and phosphopeptide derivatization identify universal stress proteins in elicitor-treated Arabidopsis. Mol. Plant-Microbe Interact. 2008, 21, 1275-1284. [CrossRef] [PubMed]

37. Callard, D.; Axelos, M.; Mazzolini, L. Novel molecular markers for late phases of the growth cycle of Arabidopsis thaliana cell-suspension cultures are expressed during organ senescence. Plant Physiol. 1996, 112, 705-715. [CrossRef] [PubMed]

38. Fawke, S.; Doumane, M.; Schornack, S. Oomycete Interactions with Plants: Infection Strategies and Resistance Principles. Microbiol. Mol. Biol. Rev. 2015, 79, 263-280. [CrossRef]

39. Seifikalhor, M.; Aliniaeifard, S.; Hassani, B.; Niknam, V.; Lastochkina, O. Diverse role of $\gamma$-aminobutyric acid in dynamic plant cell responses. Plant Cell Rep. 2019, 38, 847-867. [CrossRef]

40. Ramesh, S.A.; Tyerman, S.D.; Gilliham, M.; Xu, B. $\gamma$-Aminobutyric acid (GABA) signalling in plants. Cell. Mol. Life Sci. 2017, 74, 1577-1603. [CrossRef]

41. Carvalhais, L.C.; Dennis, P.G.; Badri, D.V.; Tyson, G.W.; Vivanco, J.M.; Schenk, P.M. Activation of the Jasmonic Acid Plant Defence Pathway Alters the Composition of Rhizosphere Bacterial Communities. PLoS ONE 2013, 8, e56457. [CrossRef]

42. Chong, J.; Wishart, D.S.; Xia, J. Using MetaboAnalyst 4.0 for Comprehensive and Integrative Metabolomics Data Analysis. Curr. Protoc. Bioinform. 2019, 68. [CrossRef]

43. Huber, A.E.; Bauerle, T.L. Long-distance plant signaling pathways in response to multiple stressors: The gap in knowledge. J. Exp. Bot. 2016, 67, 2063-2079. [CrossRef]

44. Zwart, D.C.; Kim, S.H. Biochar amendment increases resistance to stem lesions caused by phytophthora spp. in tree seedlings. HortScience 2012, 47, 1736-1740. [CrossRef] 
45. Verslues, P.E.; Sharma, S. Proline Metabolism and Its Implications for Plant-Environment Interaction. Arab. B. 2010, 8, e0140. [CrossRef] [PubMed]

46. Johnová, P.; Skalák, J.; Saiz-Fernández, I.; Brzobohatý, B. Plant responses to ambient temperature fluctuations and water-limiting conditions: A proteome-wide perspective. Biochim. Biophys. Acta (BBA) Proteins Proteom. 2016, 1864, 916-931. [CrossRef] [PubMed]

47. Lopes-Caitar, V.S.; Silva, S.M.H.; Marcelino-Guimaraes, F.C. Plant Small Heat Shock Proteins and Its Interactions with Biotic Stress; Springer: Cham, Switzerland, 2016; pp. 19-39.

48. Maimbo, M.; Ohnishi, K.; Hikichi, Y.; Yoshioka, H.; Kiba, A. Induction of a small heat shock protein and its functional roles in Nicotiana plants in the defense response against Ralstonia solanacearum. Plant Physiol. 2007, 145, 1588-1599. [CrossRef]

49. Kanzaki, H.; Saitoh, H.; Ito, A.; Fujisawa, S.; Kamoun, S.; Katou, S.; Yoshioka, H.; Terauchi, R. Cytosolic HSP90 and HSP70 are essential components of INF1-mediated hypersensitive response and non-host resistance to pseudomonas cichorii in Nicotiana benthamiana. Mol. Plant Pathol. 2003, 4, 383-391. [CrossRef]

50. Song, T.; Ma, Z.; Shen, D.; Li, Q.; Li, W.; Su, L.; Ye, T.; Zhang, M.; Wang, Y.; Dou, D. An Oomycete CRN Effector Reprograms Expression of Plant HSP Genes by Targeting their Promoters. PLoS Pathog. 2015, 11, e1005348. [CrossRef]

51. Sanchez, L.; Courteaux, B.; Hubert, J.; Kauffmann, S.; Renault, J.H.; Clément, C.; Baillieul, F.; Dorey, S. Rhamnolipids elicit defense responses and induce disease resistance against biotrophic, hemibiotrophic, and necrotrophic pathogens that require different signaling pathways in Arabidopsis and highlight a central role for salicylic acid. Plant Physiol. 2012, 160, 1630-1641. [CrossRef]

52. Deenamo, N.; Kuyyogsuy, A.; Khompatara, K.; Chanwun, T.; Ekchaweng, K.; Churngchow, N. Salicylic Acid Induces Resistance in Rubber Tree against Phytophthora palmivora. Int. J. Mol. Sci. 2018, 19, 1883. [CrossRef]

53. Camisón, Á.; Martín, M.Á.; Sánchez-Bel, P.; Flors, V.; Alcaide, F.; Morcuende, D.; Pinto, G.; Solla, A. Hormone and secondary metabolite profiling in chestnut during susceptible and resistant interactions with Phytophthora cinnamomi. J. Plant Physiol. 2019, 241, 153030. [CrossRef]

54. Lefevere, H.; Bauters, L.; Gheysen, G. Salicylic Acid Biosynthesis in Plants. Front. Plant Sci. 2020, 11, 338. [CrossRef]

55. García-Pineda, E.; Benezer-Benezer, M.; Gutiérrez-Segundo, A.; Rangel-Sánchez, G.; Arreola-Cortés, A.; Castro-Mercado, E. Regulation of defence responses in avocado roots infected with Phytophthora cinnamomi (Rands). Plant Soil 2010, 331, 45-56. [CrossRef]

56. Sorokan, A.V.; Burhanova, G.F.; Maksimov, I.V. Anionic peroxidase-mediated oxidative burst requirement for jasmonic acid-dependent Solanum tuberosum defence against Phytophthora infestans. Plant Pathol. 2018, 67, 349-357. [CrossRef]

57. Ullah, C.; Tsai, C.; Unsicker, S.B.; Xue, L.; Reichelt, M.; Gershenzon, J.; Hammerbacher, A. Salicylic acid activates poplar defense against the biotrophic rust fungus Melampsora larici-populina via increased biosynthesis of catechin and proanthocyanidins. New Phytol. 2019, 221, 960-975. [CrossRef] [PubMed]

58. Ullah, C.; Unsicker, S.B.; Fellenberg, C.; Constabel, C.P.; Schmidt, A.; Gershenzon, J.; Hammerbacher, A. Flavan-3-ols are an effective chemical defense against rust infection. Plant Physiol. 2017, 175, 1560-1578. [CrossRef] [PubMed]

59. Wang, L.; Ran, L.; Hou, Y.; Tian, Q.; Li, C.; Liu, R.; Fan, D.; Luo, K. The transcription factor MYB115 contributes to the regulation of proanthocyanidin biosynthesis and enhances fungal resistance in poplar. New Phytol. 2017, 215, 351-367. [CrossRef] [PubMed]

60. Rookes, J.E.; Wright, M.L.; Cahill, D.M. Elucidation of defence responses and signalling pathways induced in Arabidopsis thaliana following challenge with Phytophthora cinnamomi. Physiol. Mol. Plant Pathol. 2008, 72, 151-161. [CrossRef]

61. Lazebnik, J.; Frago, E.; Dicke, M.; van Loon, J.J.A. Phytohormone Mediation of Interactions Between Herbivores and Plant Pathogens. J. Chem. Ecol. 2014, 40, 730-741. [CrossRef]

62. Shimada, T.L.; Hara-Nishimura, I. Leaf oil bodies are subcellular factories producing antifungal oxylipins. Curr. Opin. Plant Biol. 2015, 25, 145-150. [CrossRef]

63. Schuck, S.; Kallenbach, M.; Baldwin, I.T.; Bonaventure, G. The Nicotiana attenuataGLA1 lipase controls the accumulation of Phytophthora parasitica-induced oxylipins and defensive secondary metabolites. Plant Cell Environ. 2014, 37, 1703-1715. [CrossRef] 
64. Li, Y.; Liu, Z.; Hou, H.; Lei, H.; Zhu, X.; Li, X.; He, X.; Tian, C. Arbuscular mycorrhizal fungi-enhanced resistance against Phytophthora sojae infection on soybean leaves is mediated by a network involving hydrogen peroxide, jasmonic acid, and the metabolism of carbon and nitrogen. Acta Physiol. Plant. 2013, 35, 3465-3475. [CrossRef]

65. Zhu, L.; Zhou, Y.; Li, X.; Zhao, J.; Guo, N.; Xing, H. Metabolomics Analysis of Soybean Hypocotyls in Response to Phytophthora sojae Infection. Front. Plant Sci. 2018, 9, 1530. [CrossRef]

66. Scharte, J.; Schön, H.; Weis, E. Photosynthesis and carbohydrate metabolism in tobacco leaves during an incompatible interaction with Phytophthora nicotianae. Plant Cell Environ. 2005, 28, 1421-1435. [CrossRef]

67. Morkunas, I.; Ratajczak, L. The role of sugar signaling in plant defense responses against fungal pathogens. Acta Physiol. Plant. 2014, 36, 1607-1619. [CrossRef]

68. Slewinski, T.L. Diverse Functional Roles of Monosaccharide Transporters and their Homologs in Vascular Plants: A Physiological Perspective. Mol. Plant 2011, 4, 641-662. [CrossRef] [PubMed]

69. Puzanskiy, R.K.; Yemelyanov, V.V.; Shishova, M.F. Metabolomics as a modern approach for the investigation of potato plant adaptation to biotic and abiotic stress factors. Sel'skokhozyaistvennaya Biol. 2018, 53, 15-28. [CrossRef]

70. Draper, J.; Rasmussen, S.; Zubair, H. Metabolite Analysis and Metabolomics in the Study of Biotrophic Interactions between Plants and Microbes. In Annual Plant Reviews online; John Wiley \& Sons, Ltd.: Chichester, UK, 2018; pp. 25-59.

71. Coelho, A.C.; Horta, M.; Neves, D.; Cravador, A. Involvement of a cinnamyl alcohol dehydrogenase of Quercus suber in the defence response to infection by Phytophthora cinnamomi. Physiol. Mol. Plant Pathol. 2006, 69, 62-72. [CrossRef]

72. Mierziak, J.; Kostyn, K.; Kulma, A. Flavonoids as important molecules of plant interactions with the environment. Molecules 2014, 19, 16240-16265. [CrossRef]

73. Treutter, D. Significance of flavonoids in plant resistance: A review. Environ. Chem. Lett. 2006, 4, $147-157$. [CrossRef]

74. Kim, H.; O'Connell, R.; Maekawa-Yoshikawa, M.; Uemura, T.; Neumann, U.; Schulze-Lefert, P. The powdery mildew resistance protein RPW8.2 is carried on VAMP721/722 vesicles to the extrahaustorial membrane of haustorial complexes. Plant J. 2014, 79, 835-847. [CrossRef]

75. Viktorova, J.; Krasny, L.; Kamlar, M.; Novakova, M.; Mackova, M.; Macek, T. Osmotin, a Pathogenesis-Related Protein. Curr. Protein Pept. Sci. 2012, 13, 672-681. [CrossRef]

76. Jalil, S.U.; Mishra, M.; Ansari, M.I. Current view on chitinase for plant defence. Trends Biosci. 2015, 8, 6733-6743.

77. Xiao, C.; Gao, J.; Zhang, Y.; Wang, Z.; Zhang, D.; Chen, Q.; Ye, X.; Xu, Y.; Yang, G.; Yan, L.; et al. Quantitative proteomics of potato leaves infected with phytophthora infestans provides insights into coordinated and altered protein expression during early and late disease stages. Int. J. Mol. Sci. 2019, 20, 136. [CrossRef] [PubMed]

78. Santos, C.; Duarte, S.; Tedesco, S.; Fevereiro, P.; Costa, R.L. Expression Profiling of Castanea Genes during Resistant and Susceptible Interactions with the Oomycete Pathogen Phytophthora cinnamomi Reveal Possible Mechanisms of Immunity. Front. Plant Sci. 2017, 8, 515. [CrossRef] [PubMed]

79. Hloušková, P.; Černý, M.; Kořínková, N.; Luklová, M.; Minguet, E.G.; Brzobohatý, B.; Galuszka, P.; Bergougnoux, V. Affinity chromatography revealed 14-3-3 interactome of tomato (Solanum lycopersicum L.) during blue light-induced de-etiolation. J. Proteomics 2019, 193, 44-61. [CrossRef] [PubMed]

80. Hallmark, H.T.; Černý, M.; Brzobohatý, B.; Rashotte, A.M. trans-Zeatin-N-glucosides have biological activity in Arabidopsis thaliana. PLoS ONE 2020, 15, e0232762. [CrossRef]

81. Dorfer, V.; Pichler, P.; Stranzl, T.; Stadlmann, J.; Taus, T.; Winkler, S.; Mechtler, K. MS Amanda, a universal identification algorithm optimized for high accuracy tandem mass spectra. J. Proteome Res. 2014, 13, 3679-3684. [CrossRef]

82. Perez-Riverol, Y.; Csordas, A.; Bai, J.; Bernal-Llinares, M.; Hewapathirana, S.; Kundu, D.J.; Inuganti, A.; Griss, J.; Mayer, G.; Eisenacher, M.; et al. The PRIDE database and related tools and resources in 2019: Improving support for quantification data. Nucleic Acids Res. 2019, 47, D442-D450. [CrossRef]

83. Cerna, H.; Černý, M.; Habánová, H.; Šafářová, D.; Abushamsiya, K.; Navrátil, M.; Brzobohatý, B. Proteomics offers insight to the mechanism behind Pisum sativum L. response to pea seed-borne mosaic virus (PSbMV). J. Proteomics 2017, 153, 78-88. [CrossRef] 
84. Salem, M.A.; Yoshida, T.; Perez de Souza, L.; Alseekh, S.; Bajdzienko, K.; Fernie, A.R.; Giavalisco, P. An improved extraction method enables the comprehensive analysis of lipids, proteins, metabolites and phytohormones from a single sample of leaf tissue under water-deficit stress. Plant J. 2020, 103, tpj.14800. [CrossRef]

85. Pino, L.K.; Searle, B.C.; Bollinger, J.G.; Nunn, B.; MacLean, B.; MacCoss, M.J. The Skyline ecosystem: Informatics for quantitative mass spectrometry proteomics. Mass Spectrom. Rev. 2020, 39, 229-244. [CrossRef]

86. Bindea, G.; Mlecnik, B.; Hackl, H.; Charoentong, P.; Tosolini, M.; Kirilovsky, A.; Fridman, W.H.; Pagès, F.; Trajanoski, Z.; Galon, J. ClueGO: A Cytoscape plug-in to decipher functionally grouped gene ontology and pathway annotation networks. Bioinformatics 2009, 25, 1091-1093. [CrossRef] [PubMed]

Publisher's Note: MDPI stays neutral with regard to jurisdictional claims in published maps and institutional affiliations.

(C) 2020 by the authors. Licensee MDPI, Basel, Switzerland. This article is an open access article distributed under the terms and conditions of the Creative Commons Attribution (CC BY) license (http://creativecommons.org/licenses/by/4.0/). 